\title{
PROMOTING REFLECTIVE PRACTICE VIA THE USE OF 5-STEP COPORA REFLECTIVE MODEL: A CASE STUDY OF EAST MALAYSIAN ESL PRE-SERVICE TEACHERS
}

\author{
Wei Ann Ong ${ }^{a}$, Suyansah Swanto ${ }^{b}$, Asmaa AISaqqaf ${ }^{c}$, Jia Wei Ong ${ }^{d}$ \\ ('haroldwa22@gmail.com, bsuyansah@ums.edu.my, ${ }^{\mathrm{c} a s m a 3030 @ y a h o o . c o m, ~}$ \\ p3521@pps.umt.edu.my) \\ a, b, Universiti Malaysia Sabah \\ Jalan UMS, 88400 Kota Kinabalu, Sabah, Malaysia \\ ${ }^{d}$ Universiti Malaysia Terengganu \\ 21300 Kuala Terengganu, Terengganu, Malaysia
}

\begin{abstract}
Teachers who are reflective are found to be more able to develop themselves professionally. However, pre-service teachers were found to be in need of explicit instructions on reflective practice. This paper presents the results of an investigation on the use of the 5-step Cognition Practice Observation Reflection Action (CoPORA) reflective model among a group of Malaysian ESL pre-service teachers enrolled in an Institute of Teacher Education. A qualitative case study design was utilised, where the model was taught to a group of 13 pre-service ESL teachers who later completed the second phase of their teaching practice. The data for this study comprised the respondents' entries in their practicum reflection forms, reflective video blogs and focus group interviews. Results showed that respondents have moved from engaging in the lower levels of reflection to a higher pedagogical reflection. They also responded favourably to the use of the 5-step CoPORA reflective model for its structured approach. Nevertheless, the respondents lamented their struggles in rationalising issues faced and in suggesting suitable solutions. It is proposed that the pre-service teachers were shown exemplars of critical reflection to help them see the level at which they ought to reflect. Alternatively, teacher educators can explore a dialogic or collaborative approach to reflection so pre-service teachers can work with one another to further develop their reflective practice.
\end{abstract}

Keywords: ESL, reflective model, reflective practice, pre-service teachers

DOI: http://dx.doi.org/10.15639/teflinjournal.v32i1/72-96 
In its quest to strengthen its education system, Malaysia has included the transformation of teaching into a profession of choice as one of its shifts in its 2013-2025 Malaysian Education Blueprint. Hence, institutions of higher learning have been entrusted with the monumental task of producing preservice teachers (PSTs) who possess all the relevant skills and knowledge to teach in Malaysian schools upon graduation. Reflective thinking is one of the competencies that a PST should demonstrate as underlined in the Malaysian Teacher Standard or Standard Guru Malaysia (Bahagian Pendidikan Guru, 2009), which also spells a list of competencies that Malaysian teachers should demonstrate (Goh, 2012). Therefore, reflective practice is made a component in the Malaysian teacher education programme and is mainly incorporated in the teaching practice which is more commonly known as practicum.

Engaging in reflective practice is touted as one of the possible ways to support PSTs through their practicum as it can assist them to justify their selection of teaching methodology and pedagogical approach and to determine how they can improve themselves (Chien, 2014; Mukhtar et al., 2018). Nevertheless, a review of past studies would lend to the argument that Malaysian PSTs are struggling in their engagement of reflective practice, and they lack strategies and reflective models to engage in reflective practice. Hence, this case study attempted to promote a higher level of reflective practice among ESL PSTs via a reflective model named CoPORA.

\section{Reflective Practice of Pre-service Teachers in Malaysia}

Past studies have extolled the virtues of teachers who are reflective practitioners. They are teachers who would possess good reasoning skills in tackling ill-structured problems (Wlodarsky \& Walters, 2010) and demonstrate resilience in encountering the initial shocks of the beginning years of teaching (Moradkhani et al., 2017). As pre-service teachers begin to hone their craft as teachers during their teaching practice, it is imperative that they engage in reflective practice. Farrell (2016) posits that engaging in reflective practice helps PSTs to articulate and reflect on their beliefs, with the hope that a new level of awareness could invite a potential re-evaluation of their practices.

However, the ability to engage in reflective practice remains elusive to PSTs. Analysis of written reflections by the PSTs revealed to be descriptive and heavily focused on technical issues (He \& Prater, 2014). While the PSTs have been found to be able to recall and critically discuss instances in their lessons, 
they may not necessarily reflect deeply enough to reach the level where problem-solving and examination of one own's practice occurs (Ciampa \& Gallagher, 2015; Goldman \& Grimbeek, 2015). Closer to the context of this study, studies conducted in Malaysia have revealed the weak level of reflection among PSTs, where the reflections were found to be at the surface level. This occurs in both public universities and Institute of Teacher Education where most teacher education programmes are conducted (Ong et al., 2017; Ong et al., 2018; Yaacob et al., 2014). PSTs were found to be unable to reflect critically and propose solutions to problems. They would focus instead on technical issues that they encounter in the classroom (Suppiah et al., 2019).

In explaining the inability of PSTs to reflect critically, Kori et al. (2014) postulated that reflection can be difficult to pre-service teachers as their reflection is shaped by the concrete experience that they have encountered. As they are relatively new to the practice of teaching, their limited knowledge of and exposure to development of teaching methodology hinder them from truly reflecting on their teaching performance (Andreotti, 2006; Bryan et al., 2009; Krishnan \& Yunus, 2017). Past research has also indicated shortcomings of the teacher education programmes in creating conducive learning environment for the development of critical reflection (Lim et al., 2016; Ong et al., 2017). Therefore, it is pivotal for PSTs to develop the ability to engage in reflective practice independently as a means for them to develop themselves professionally as competent teachers.

In order to promote the criticality in reflective practice among PSTs, past research has highlighted the need to structure the reflection process itself, as the structure supports them to think about, describe, analyse, and respond to the learning of their students (Garza \& Smith, 2015; Rodgers, 2002). Furthermore, a structured reflective practice is essential in developing teacher professionalism and discouraging them from seeking quick solutions to problems in the classroom (Korthagen \& Vasalos, 2005). Studies undertaken in the past have proven the effectiveness of reflective strategies in helping PSTs to reflect critically. Hrevnack (2011) developed the Guided Reflective Observation and Analysis Model (GROAM) to promote reflective thinking skills among PSTs, while Bloomquist (2016) studied the use of reflective framework known as LORAA to assist early childhood science teachers in increasing the level of their reflectivity. However, both Hrevnack and Bloomquist's studies were conducted in foreign contexts and have focused on 
teachers who taught subjects other than ESL. While there are a number of reflective models which can be adopted for reflective practice, these models have either centred solely on the beliefs and cognition of the teacher (such as Farrell's reflective framework for TESOL teachers), or have concerned itself only on the event in the teaching and learning process, ignoring the teacher's beliefs altogether (such as Kolb's stages of learning and Bain et al.'s 5R reflective framework). As Afshar and Farahani (2015) also urge teacher educators to take a primary role in providing training for PSTs on the matter of reflective thinking and development of teaching skills, it is based on these arguments and gaps that the CoPORA reflective model was developed and studied in this research.

\section{CoPORA Reflective Model}

The 5-Step CoPORA reflective model was developed from 3 main models of reflective practice: Kolb's (1984) stages of learning, Bain et al.'s (2002) 5R reflective framework, and Farrell's (2015) reflective practice framework for TESOL professionals. These models were combined as they provide a systematic and structured approach to engage in reflective practice with the practitioner's personal teaching beliefs or cognition being the starting point of the reflective process. Adopting CoPORA reflective model would facilitate a reflective process which begins with the teacher's personal beliefs and ends with actions that could ultimately lead to the change of the PSTs teaching practice for the better.

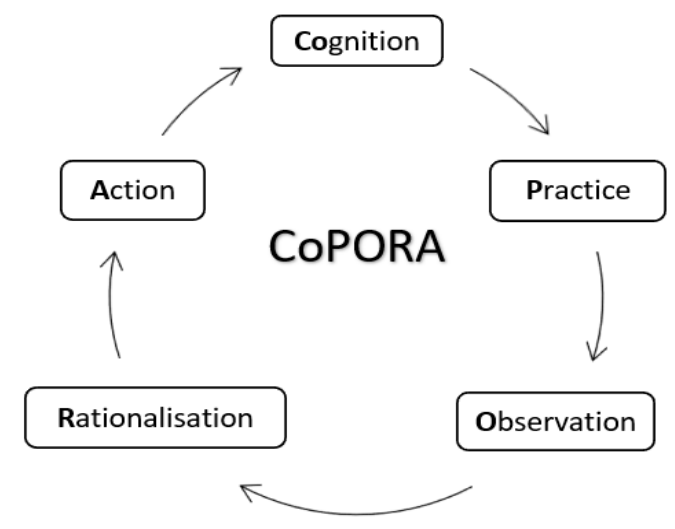

Figure 1. Steps in the CoPORA reflective model 
When the PSTs have finished teaching a lesson, they are encouraged to engage in reflective practice by using the CoPORA model. The model starts with Cognition. This stage is created based on the concept of teachers' cognition, which refers to the interplay of beliefs, knowledge, and thoughts which teachers hold onto and draw from in carrying out their professional work (Borg, 2015). In the Cognition stage, teachers elucidate their rationales for their lesson planning and selection of activities and resources. The second stage of CoPORA is Practice, where teachers describe the practice and the events that have taken place in the classroom. The practice is essentially the articulation of the cognition as a practitioner brings his or her cognition into reality. The third stage is observation, where the pre-service teachers mentally recalled what has transpired in the lesson that they have taught. Toom et al. (2015) postulate that pre-service teachers can be coached to discover the gap between what they want to achieve in their lessons and how they did in the actual lesson taught. In the context of this model, the contrast was between Cognition and Observation. This is because reflection can only be triggered when there is a purposeful cognitive undertaking via the actions of noticing a specific incident or situation (Lane et al., 2014).

The fourth step is Rationalisation. At this stage, teachers are to provide reasons for the challenges that they have encountered in their classroom and provide possible explanations for them. Korthagen (2017) recommends teachers to spend adequate time to conduct rational analysis of the issues faced in lessons, focusing on a deep understanding of the roots of the problems. Otherwise, the reflection would lead to superficial, ineffective solutions which will only perpetuate the issues faced by the teachers. The last stage is Action, where teachers begin formulating possible solutions to their problems. Expert teachers are able to filter problems in the classroom and subsequently brainstorm possible pedagogical solutions to overcome the issues that they faced in their lessons (Haverback \& Parault, 2008). A critical aspect at the Action stage is the thinking about "what could have happened, instead of what did happen" (Mohammed, 2016, p. 26), where a teacher mulls the possible outcomes he or she should use as an alternative approach to solve the problem.

In developing the reflective framework which can result in changes to personal beliefs and teaching practices, it is paramount to direct the reflective task to focus on only critical incidents and not daily events (Wong et al., 2015). Tripp (1993) postulates that a critical incident could stem from either an 
ordinary or a significant, highly impactful event that occurs during teaching and learning. In this study, the respondents were coached to use the CoPORA reflective model to focus only on a particular stage of their lesson or incident which occurred in their lesson. This is to ensure focus and allow the reflective model to assist the PSTs in their reflective practice.

Therefore, the objectives of the study are:

1. to investigate whether the respondents can demonstrate the use of CoPORA reflective model via vlogs,

2. to determine whether the use of CoPORA reflective model would result in a change in the respondents' level of reflective practice,

3. to ascertain the respondents' perception towards the use of CoPORA in their post-lesson reflections.

4. to explore any possible challenges faced by the respondents' use of CoPORA as part of their reflective practice.

\section{METHOD}

In this study, the researcher wished to capture the respondents' actions, thoughts, opinions, and behaviour as a result of the use of CoPORA reflective model in their reflective practice. Therefore, case study approach was used as it allows researchers to understand the respondents' experiences and lived realities (Merriam, 1998). The case study approach would also be interpretive in nature, whereby it was utilised to analyse and interpret a studied phenomenon (Merriam, 2007), which was pre-service ESL teachers engaging in reflective practice.

Before proceeding with the implementation of a case study, it is paramount to set the unit of analysis (Yin, 2014), which can be a person, a small group, an organisation, a programme, or even a neighbourhood (Merriam, 2007). In this study, the unit of analysis referred to the respondents, comprising a class of 14 pre-service ESL teachers who had completed two phases of their practicum in urban and sub-urban primary schools of a city in East Malaysia. Prior to the data collection process, the respondents were trained to use CoPORA and were encouraged to adopt the reflective model in their reflective practice throughout their teaching practice. Three instruments were used to gather the necessary data needed for the study, namely the vlogs, 
the Practicum Reflection (PR) forms used by the respondents in their practicum, and the focus group interview.

In order to demonstrate their evidence of mastery in the use of the model, the respondents were requested, during the period when they underwent their second teaching practice, two reflections using the model presented via the medium of video blogs or vlogs. A vlog was chosen to be the medium to present the respondents' reflection using the CoPORA reflective model as it is a more expressive and versatile approach to presenting ideas (Baskara, 2017; Taylor, 2013). With the prevalence of the use of mobile devices such as tablet computers and smart phones, people can use vlogs to share their thoughts, looks, and feelings with everyone around them almost instantaneously (Sanchez-Cortes et al., 2015). The vlogs were recorded by the respondents and later uploaded into a closed Facebook Group. The researcher would later transcribe and subsequently analyse the content using the steps in the CoPORA reflective model.

Next, a content analysis of the PR forms was carried out to ascertain whether there is a change in the level of the reflective practice of the PSTs as a result of the use of CoPORA. In the campus of ITE where the data was gathered, the PSTs were required to complete a PR form whenever they had finished conducting a lesson. The form consists of two sections. In the first section, there are six rows of paired columns for PSTs to write down the strengths and weaknesses of every stage in their lesson. Meanwhile, in the second section, PSTs must write down their suggestions for improvement and how the suggestions would impact their lessons in the future. Therefore, the form has a total of 14 columns that can be filled out although the PSTs were not obligated to fill out all. As the respondents had regularly filled out only 10 of the 12 columns provided in the first section, the content analysis only examined 10 columns of Section One and the two questions in Section Two.

A total of 14 respondents were recruited to participate in this study. The respondents were given a briefing on the research project and consent was sought for their participation. They were given the assurances that their participation was anonymous and they could pull out at any stage of the study. Nine of the respondents of the study had consented for their practicum reflection forms to be examined for this research. The PR forms filled out by the respondents from two different time periods, that is, Semester 5 (prior to the introduction of CoPORA) and Semester 7 (after the introduction of 
CoPORA), were included in the study. For every respondent, one PR form was randomly chosen from Week 3, 6, 9, and 12 of their practicum. Larrivee's (2008) Reflective Practice Assessment Tool (LRPAT) was adopted as the rubric to examine the comments written down by the respondents.

Larrivee (2008) has developed LRPAT as a tool for student teachers to assess their level of reflective practice. Her rubric has four levels, which include Pre-reflection, Surface Reflection, Pedagogical Reflection, and Critical Reflection. All levels have 14 descriptors each, with the exception of Surface Reflection, which has 11 descriptors. The description of each level and its general characteristics is shown in Table 1 below.

Table 1. LRPAT's four levels of reflections and their characteristics

\begin{tabular}{|l|l|}
\hline $\begin{array}{l}\text { Level of } \\
\text { reflection }\end{array}$ & Characteristics \\
\hline Pre-reflection & $\begin{array}{l}\text { The teacher rationalises the events of the classroom in general } \\
\text { without reference to any theories or other relevant situations. }\end{array}$ \\
\hline $\begin{array}{l}\text { Surface } \\
\text { Reflection }\end{array}$ & $\begin{array}{l}\text { A teacher's decision-making is guided by prior experience though } \\
\text { s/he begins to differentiate the needs of his or her students. }\end{array}$ \\
\hline $\begin{array}{l}\text { Pedagogical } \\
\text { Reflection }\end{array}$ & $\begin{array}{l}\text { A teacher makes conscious efforts to reflect about his or her } \\
\text { teaching practices and the potential outcomes of their students. }\end{array}$ \\
\hline $\begin{array}{l}\text { Critical } \\
\text { Reflection }\end{array}$ & $\begin{array}{l}\text { A teacher regularly examines his/her own pedagogical philosophies } \\
\text { and teaching beliefs. Where possible, the teacher tries to promote } \\
\text { democratic values in the classroom and ascertain the social and } \\
\text { ethical implications of his or her classroom practices }\end{array}$ \\
\hline
\end{tabular}

The descriptions for every level were matched against the comments written by the respondents in the PR forms. The findings were subsequently classified under five categories: pre-reflection, surface reflection, pedagogical reflection, critical reflection, and unfilled, i.e., for columns which were left empty by the respondents.

As a follow up to the analysis result of the PR forms, the respondents were interviewed in four sessions of Focus Group Interview (FGI). The FGIs were conducted to confirm the findings of the survey and elicit more thoughts from the respondents on the study. FGI was adopted as many research participants perceived it as less threatening, and the rapport among the respondents and between the researcher and the respondents was well-established. This is because the respondents had been studying together for the past five semesters 
and the researcher had the privilege of teaching the respondents in one of the semesters. The interviews were first transcribed, then analysed, coded, and categorised using qualitative analysis software ATLAS.Ti. The categories were later grouped to represent salient clusters of themes. The names of the respondents were replaced with pseudonyms in order to ensure anonymity.

Several means have been undertaken to ensure this study possesses a level of trustworthiness in the qualitative data gathered (Guba, 1981). The results of the study had undergone member checking with the participants to ensure that the data is understood within its contextual meaning as expressed by the respondents (van Manen, 1983). The transcribed interviews were later shared with the respondents in a follow-up session in order to give the respondents the opportunity to peruse and further clarify themselves on points which were vague or obscure during the FGI. The three sources of data gathered for this study also functioned to verify each other to ensure consistency in the findings derived from the study via triangulation. An ESL lecturer with no vested interest in this study, who is from the same institution where the respondents were based, has been recruited to assess the level of reflection demonstrated by the respondents in the PR forms using the LRPAT rubric. Engaging a neutral assessor in the research process was deemed crucial in providing objective perspectives and to counter "subjectivity and interpretive relativism that are seen as both advantage and liability in qualitative research" (Sandelowski, 1998, p. 467).

\section{FINDINGS AND DISCUSSION}

The study has identified four findings to achieve the four research objectives. Findings 1 to 4 each corroborates with the first, second, third and fourth research objectives respectively. While the CoPORA has been found to achieve a certain level of success, several hindrances persist in the PSTs' journey to achieve critical engagement in their reflective practice.

\section{Finding 1: Respondents demonstrated ability to use CoPORA in vlogs.}

In order to ensure that the respondents of this study were able to demonstrate their understanding and subsequently their mastery of the CoPORA reflective model, they were requested to post two vlogs that contained their reflections by following the steps of the reflective model. 
Respondents' excerpts which showcased each of the 5 stages of CoPORA reflective model revealed that the respondents generally did not face difficulty in using the model. In the vlogs, the respondents first introduced the lesson and the stage that they would be reflecting on before proceeding to reflect on the Cognition step of the model. The respondents did that by first sharing the activity that they have conducted in class and then proceed to provide the rationale for their decisions.

"Hi guys, so this is my first reflection video. My class is a Year 4 class, which consists of mixed ability pupils. My topics would be solar system, which is week 9. The thing was I wanted the pupils to recite a poem together with the class and then I would want them to perform as a group."

Vlogs- Diane Round 1

"I encouraged them to ask as many of their friends as they can. This is to ensure that they can increase their chances of interacting with people with high proficiency, which will encourage them to speak more and listen to their friends."

Vlogs- Gary Round 1

Most respondents have had no issue with articulating their rationale for the selection of activity. Most of their answers are learner-centred, hoping for their learners to achieve certain skills based on the learning objectives set. Their cognition, however, were mostly to achieve the objectives of the lesson, rather than showing the underlying aspect of their personal beliefs about language teaching and learning. This could be explained in that being pre-service teachers, their immediate concern was to complete their lessons assigned to them in teaching practice, so the focus would be to successfully complete the lesson objectives.

The next stage is Practice, where the respondents shared what they have enacted in their classroom. This stage has consistently been the longest part in the vlogs, as the respondents took great effort in describing what they did in their lessons.

"After that, I asked them to read the text silently for about 3 minutes and after 3 minutes, I told them that they were going to play a short game and I gave each pair (of students) red and green colour sticks. I used Powerpoint slides to flash the questions."

Vlogs- Alia round 2 
82 TEFLIN Journal, Volume 32, Number 1, January 2021

So there were 7 groups and each group was required to produce 6 simple sentences with adverbs based on their respective sentence strip number. So the number on their sentence strips determined which sentences that they need to create with adverbs based on the guidance given from the previous practice stage.

Vlogs- Olivia Round 1

The third stage is Observation. At this stage, the respondents were asked to report on what they can notice for themselves from the activity that they have conducted. They were asked to observe learner behaviours and seatwork as indications of how well they did in the lesson that they were reflecting.

Through my observation, they enjoyed and understood the story well, but I noticed that some of them did not understand the instruction well and most of them just copied the original story in the text with no alternative ending inside. So, only a few pupils came out with stories of their own.

Vlogs- Mikail Round 1

From my observation, I saw that some of the pupils did not contribute to the group discussion. While the other two were discussing the group answer to the questions, the other two were talking to each other. Besides, I also saw pupils fighting over the answer cards.

Vlogs- Lily Round 1

As can been seen in the excerpt above, the respondents reported their pupils' reaction, performance and their written outcome in observation. These served as evidences for them to engage in their reflection and determine the issues that they are facing in their reflective vlogs. As a continuation to what they have observed for themselves in the Observation stage, the next stage is Rationalisation. In this stage, they would determine what are the possible reasons behind the issues that they have noticed for themselves earlier.

...because I just asked them to go to their pairs and gave them the template. I didn't explain to them what they are actually supposed to do. And these weaker pupils they probably needed more guidance because they were weak at writing.

Vlogs- Carmen Round 2

What I have learnt next is that the higher proficiency pupils did not do a great job teaching the lower proficiency ones. I also just roamed around the class and it's my fault that I didn't actually encourage them to teach their peers. I just told them to teach and I didn't give them appraisal or anything.

Vlogs- Richard round 1 
The reflection of most of the respondents were mostly introspective, where they examined their own shortcomings in causing the learners not to achieve the lesson objectives. They also relate it to the needs and characteristics of their learners, and how they were not able to cater to them. In response to the reasons given by the respondents in the rationalisation stage, the pre-service teachers would proceed with the recording of vlogs in the Action stage. This is the stage where they proposed possible ideas and actions which they could take to remedy the issues they faced.

Maybe I should have broken (the instruction) part by part and used mah-jong paper to write a clear instruction on the whiteboard and told them that they shouldn't take the picture because everyone was so impatient maybe they thought it was like a running man, but they only needed to find 3 pictures.

Vlogs- Pamela round 1

Another possible action that I could take is that the group members could take turns to go around and search for the answers instead of going together all at once. If they take turns they can focus on specific questions and they can save more time and it will be less of a hassle.

Vlogs- Candice round 2

In the excerpts, one can observe that the respondents not only proposed the suggestions for their issue, but also offered the possible justification and the impact that their decision would have on the issue that they faced. They make prediction of how their suggested actions could affect their pupils' learning, or they could better obtain the lesson objectives based on the issue reflected. The examination of the vlogs' content provided the evidences of the respondents' ability to reflect using the CoPORA reflective model, which also supported claims by Baskara (2017) and Taylor (2013), who concurred that vlogs can be a good medium to present reflection. In this study, reflective practice could be presented and captured aptly via the recording and sharing of vlogs.

\section{Finding 2: Improvement in reflective practice only reached pedagogical reflection.}

In order to determine if there is a change in the level of reflective practice demonstrated by the respondents as a result of the CoPORA reflective model, the results of the respondents' reflective entries before and after they were trained in the use of the model were compared. The results of the analysis are 
shown in Table 2. A total of 432 entries from the respondents' PR forms were examined for each time period.

Table 2. Level of Reflection in the Columns of PR Forms before and after CoPORA $(n=432)$

\begin{tabular}{|l|c|c|c|c|}
\hline & \multicolumn{2}{|c|}{ Pre-CoPORA } & \multicolumn{2}{c|}{ Post-CoPORA } \\
\hline $\begin{array}{l}\text { Level of } \\
\text { Reflection }\end{array}$ & $\begin{array}{c}\text { Total number } \\
\text { of columns }\end{array}$ & $\begin{array}{c}\text { Percentage } \\
\text { (\%) }\end{array}$ & $\begin{array}{c}\text { Total number } \\
\text { of columns }\end{array}$ & $\begin{array}{c}\text { Percentage } \\
(\%)\end{array}$ \\
\hline Unfilled & 167 & 38.66 & 125 & 28.94 \\
\hline Pre-reflection & 138 & 31.94 & 133 & 30.79 \\
\hline $\begin{array}{l}\text { Surface } \\
\text { Reflection }\end{array}$ & 94 & 21.76 & 80 & 18.52 \\
\hline $\begin{array}{l}\text { Pedagogical } \\
\text { Reflection }\end{array}$ & 33 & 7.64 & 94 & 21.76 \\
\hline $\begin{array}{l}\text { Critical } \\
\text { reflection }\end{array}$ & 0 & 0.00 & 0 & 0.00 \\
\hline TOTAL & $\mathbf{4 3 2}$ & $\mathbf{1 0 0 . 0 0}$ & $\mathbf{4 3 2}$ & $\mathbf{1 0 0 . 0 0}$ \\
\hline
\end{tabular}

As can be seen in Table 2, the percentage of columns for Unfilled, Pre and Surface reflection have decreased while the percentage of columns for pedagogical reflection has increased almost three-fold. In the FGI, the respondents have also praised the usefulness of the CoPORA reflective model in helping them to structure their thinking.

If we did not participate in this project we wouldn't realise a more systematic and analytic way of doing reflection because previously we only know the basic and that is the simplest way of doing reflection ... based on strengths and weaknesses but now we know we can be more critical of doing our reflection, that's what I noticed.

FGI- Izzati

I think it was very beneficial for me because previously I only think about my weakness and strengths. But now I use the model to structure and arrange what I reflected on.

FGI- Diane

Before this, I did not really know how to reflect properly, I would just write the mistakes and then suggest the improvements. I didn't really know that there is a 5 step structure that you can follow. CoPORA has actually helped me in reflecting and in my practicum.

FGI- Ruth 
The respondents have compared their experience of their first practicum and second practicum and have reported that prior to the use of CoPORA reflective model, they have only thought about their strengths and weaknesses, which could be due to the prompts given by the PR forms. However, in the second phase of practicum the model helped them to reflect deeper and further than what they were used to. As the respondents followed the stages in CoPORA, they would reflect on their cognition, recall the event, analyse the issues and provide possible solutions to what they have encountered. The improved level of reflective practice as shown in the PR forms were also agreed upon by the respondents in the interview. Past studies have shown that pre-service teachers perform poorly in levels of reflective practice due to the fact that they lack conception of what constitutes a good reflection, and at what level and to what extent they should reflect (Goldman \& Grimbeek, 2015). Therefore, providing the respondents with a structured reflective model would change the way the PSTs approach their reflective practices. CoPORA reflective model allowed them to extend their reflection to cover more aspects and reflect at a deeper level. This finding was also consistent with the previous studies which supported the use of explicit framework in scaffolding reflective practice among pre-service teachers (Bloomquist, 2016; Goldman \& Grimbeek, 2015; He \& Prater, 2014; Hrevnack, 2011)

Nevertheless, it was evident in the analysis of the PR forms that the respondents were not able to reflect at the level of critical reflection. The contributing factors could be one, the CoPORA model did not push them to reflect at Larrivee's critical reflection; two, the PR forms that they used were not able to prompt them to reflect more critically. The respondents' opinion helped to shed some clues.

the columns (PR forms), I felt like it is very limited for me to write ... before I did the video I wrote a draft so it's very hard for me to put what I wrote in the draft into the columns...

FGI- Diane

the space in the PR form was limited but when you come here (CoPORA) it is different, you can write whatever that you want, more freedom to write about what action you did

FGI- Pamela

in the form that was given the space is very limited, sometimes I have 3 weaknesses but I cannot write them all down. I can only state and by using this 
86 TEFLIN Journal, Volume 32, Number 1, January 2021

(COPORA) we can explain why those weaknesses happen but using the form we cannot really state them

FGI- Alia

While the respondents were happy to use CoPORA reflective model because they were able to reflect further and deeper, they felt that the PR forms that they used have limited their ability to write their reflection with more detail and depth. Mann and Walsh (2013) warned that the prescriptive stance in teacher education towards PSTs' engagement in reflection could lead to a 'recipe-following', mechanised task. This study proved that the prescriptive stance could have manifested in the rigid structure of the practicum reflection form itself, where its columns and prompts may have boxed the reflection of the PSTs and they were not able to reflect beyond the given prompts. The respondents' preference for free-form writing also supports the notion that when PSTs are given a structure to reflect critically, there would not be a need for a structured reflection form, especially when the format of the forms is not in harmony with the steps in CoPORA, as seen in the context of this study.

\section{Finding 3: CoPORA Model is perceived to be structured and helpful.}

When asked about their perception of the CoPORA reflective model, the respondents have opined that the model is very helpful and useful. They credited the model for helping them to make improvements in their reflective practice, particularly in their post lesson reflection. The respondents have given positive feedback on the model, particularly its structured and organised approach in engaging reflection.

CoPORA was very clear for me. I know that I need to start from cognition, go here (practice), go here (observation), go here (rationalisation) and then end here (action) so it's a very structured, very organised way of doing reflection.

FGI- Richard

It was explained in stages, so it helped me to think about what I should do. First I need to do the cognition, then the practice. Next, I need to observe, then I need to do my rationale and I need to do some action. It helped me to manage my thoughts very well.

FGI- Hannah 
Ong et al., Promoting Reflective Practice via the Use of CoPORA Reflective Model 87

It helped me to really structure what I want to write in my reflection and rather than just stating the strengths and weaknesses, by using this model I can see like my reflection more structured.

FGI- Alia

The feedback from them would be the result of addressing the specific need of the pre-service teachers in their reflective practice, where they struggled to reflect critically due to not having a structured method to begin their reflective practice.

So when you asked us to just choose one stage and focus on that actually we can dig out more information and actually go 'wow, ok' I never think that it is a problem that I really need to look deeper.

FGI- Ruth

I have a very positive feeling about the model because it was very helpful and it helped me to focus on all these elements.

FGI- Diane

It makes it easier to do my reflection on the daily basis. At least I know already my focus and what I should reflect.

FGI- Pamela

The focus here is paramount, as the PSTs were directed to go beyond mere reporting and describing of the events in the classroom but to focus on the issues, the reason behind the issues and the way to remedy it. The focus on a critical incident would ensure effective reflective practice, as pre-service teachers would be able to make connections between their teaching methodology and the application of theories in real-life context (Mohammed, 2016; Yang, 2009). The finding also echoed the importance of a systematic approach to help pre-service teachers engage in reflective practice, and the success of the approach translates into the ability of the respondents to reflect on the higher levels. The steps in the reflective model act as a scaffolding which can help pre-service teachers to achieve critical reflection during the reflective process (He \& Prater, 2014). While reflective practice was challenging to the respondents, the use of CoPORA reflective model was instrumental in "structuring the tasks that may initially be beyond the teachers' capabilities so they can focus without being overwhelmed" (Bloomquist, 2016, p. 5). 
Finding 4: Two stages in CoPORA model were difficult to execute.

In the analysis of the practicum reflection (PR) forms filled out by the respondents for their practicum, it was discovered that the respondents did not make much improvement in two areas: to propose actions for improvement, which is the column 11 in PR forms, and to project the impact of their suggested actions, which is the column 12 in PR forms. As seen from Table 3, of the 64 entries analysed for column 11 and 12, the number of unfilled columns, particularly Column 12, remained high despite the respondents having been trained to use the reflective model. For column 11, though a number of respondents have managed to demonstrate the level of pedagogical reflection, the number of surface reflection remained relatively high compared to the entries with pedagogical reflection. This is more apparent as the column 12 is not explicitly included in the CoPORA reflective model, but column 11 is explicitly included in the Action stage of the model.

Table 3. Level of Reflective Practice Shown by Respondents for Columns 11 and 12

\begin{tabular}{|l|c|c|c|c|}
\hline \multirow{3}{*}{ Level } & \multicolumn{2}{|c|}{$\begin{array}{c}\text { Column 11 - Suggestion } \\
\text { Action for Improvement }\end{array}$} & \multicolumn{2}{c|}{$\begin{array}{c}\text { Column 12 - Impact of the } \\
\text { suggested Action }\end{array}$} \\
\cline { 2 - 5 } & $\begin{array}{c}\text { Pre- } \\
\text { CoPORAVIL }\end{array}$ & $\begin{array}{c}\text { Post - } \\
\text { CoPORAViL }\end{array}$ & $\begin{array}{c}\text { Pre- } \\
\text { CoPORAVIL }\end{array}$ & $\begin{array}{c}\text { Post - } \\
\text { CoPORAViL }\end{array}$ \\
\hline Unfilled & 7 & 3 & 26 & 18 \\
\hline Pre & 3 & 0 & 0 & 0 \\
\hline Surface & 22 & 15 & 7 & 8 \\
\hline Pedagogical & 4 & 18 & 3 & 10 \\
\hline Critical & 0 & 0 & 0 & 0 \\
\hline Total & $\mathbf{3 6}$ & $\mathbf{3 6}$ & $\mathbf{3 6}$ & $\mathbf{3 6}$ \\
\hline
\end{tabular}

As there are 5 stages to the CoPORA reflective model, the respondents were invited to comment on the stages of the model. Their responses lamented the struggles they faced with some of the steps in the CoPORA reflective model. Though the model provided focus and area for them to reflect on, to execute the thinking required for some of the stages remained a monumental task.

As for me Action was quite challenging because like what Fanny said sometimes I just think by myself and I didn't discuss with others. So I would think this may be the only solution to my problem.

FGI- Hannah 
For me the Action. Sometimes I struggled to think about what are the future actions that I can take in order to improve my lesson"

FGI- Alia

I also agree with Hannah (the Action stage) because I don't think I'm creative enough in creating solutions"

FGI- Mikail

The respondents who struggled with the Action stage of the CoPORA Reflective Model attributed their inability to a lack of creativity on their part, where they were not able to suggest effective measures to tackle the issues that they face in their lessons. On the other hand, some respondents reported their struggles with the Rationalisation stage of the Model.

For me the Rationalisation part. Sometimes it's a bit challenging because I didn't talk to anyone about the problem so I just think that oh maybe that is the problem.

FGI- Fiona

To be honest I face some difficulties in doing one of the steps, which is Rationalisation, because I think it is very hard to find the cause of the problem of that the pupils were facing. So I spent a lot of my time thinking what could possibly cause this problem?

FGI - Ruth

I have troubles differentiating between the observation and rationalisation part.

FGI- Richard

While the respondents approved the CoPORA reflective model as it helped them to structure their reflective practice, they also admitted stages in the model such as Rationalisation and Action were particularly challenging for them. This finding contrasted Mena-Marcos et al.'s (2013), in that pre-service teachers experienced difficulty in assessing their own practice and observing their learners' performance in their lessons. It is very likely that the challenges encountered by the respondents were due to a lack of sufficient input or a lack of relevant skills on how to engage in reflective practice.

The insights made echoed the argument put forth by Farrell (2019). He argued that pre-service teachers need to learn sub-skills of reflection, such as how to articulate their beliefs, gather evidence of their teaching, understand the evidence and propose solutions. The argument that pre-service teachers need to learn sub-skills of reflection became clear as the respondents in the study named the stages of Rationalisation and Actions as difficult even when they 
have received training in using the CoPORA reflective model. Both stages are the steps in CoPORA which require the the pre-service teachers to master skills listed by Farrell in order for them to execute the steps effectively. Sherin and Russ (2014) opine that teachers who possess teacher noticing ability would be able to gain the skills of knowledge-based reasoning. They urged pre-service teachers to be trained in both observing and reasoning ability so that they are better equipped to bring about changes in the classroom. In this case, the PSTs could have been more adept in using the CoPORA reflective model had they also been equipped with the sub-skills which were proposed by Farrell (2019).

\section{CONCLUSIONS}

This study was conducted with an intention to investigate whether the use of a structured reflective model in the form of the CoPORA model could promote a higher level of reflective practice among pre-service ESL teachers. The study reported positive outcomes in that: one, the respondents demonstrated the ability to use the model via vlogs; two, a higher number of reflective entries achieving the pedagogical reflection level and above was recorded; three, favourable reviews were made by the respondents about the use of the CoPORA reflective model. However, there were no entries that reached critical reflection and the respondents reported struggling with the rationalisation and the action stages in the CoPORA reflective model.

The findings of this study revealed that though the CoPORA was able to provide a structured approach in guiding pre-service teachers to engage in reflective practice, some of the shortcomings as evidenced in the practicum reflection forms and focus group interviews need to be addressed. First, there is a need to provide additional or different methods of coaching pre-service teachers on how to use CoPORA, possibly via think-aloud protocol or in combination with other materials, such as video analysis. In addition, concrete examples which demonstrate the reflection at the pedagogical and critical levels can be shared with the respondents as a means to help them aspire to achieve in their reflective practice. This would then elevate the PSTs' ability to engage in reflective practice at the pedagogical and critical reflection levels, as shown in LRPAT. In addition, the nature of the reflective task would have to be open as well, as the practicum reflection forms have been found to limit the 
respondents' ability to reflect despite their use of the CoPORA reflection model.

The development of critical reflective practice among pre-service teachers remains a challenge. The abilities to identify reasons behind classroom issues and devise appropriate solutions may come with more exposure and experience to classroom teaching. Nevertheless, teacher educators can play a more significant role in coaching and scaffolding reflective practice among PSTs, rather than leaving the PSTs to struggle with their reflective practice and their practicum teaching until they eventually mastered the elusive skills. Other than strengthening the supporting skills which are pivotal to the critical engagement of reflective practice, the study also urges for future studies to explore reflective practice in a community or collaborative setting. The dialogic nature of interaction among the PSTs themselves or among PSTs with their mentors or supervisors could shed more light on the reflective practice of the PSTs. Bloomquist's (2016) study revealed that teachers who participated in the reflective sessions in a community were found to have improved significantly in their level of reflectivity in their teaching practice. This research direction might yield more insightful discoveries and perhaps bring even more benefits to the PSTs in their reflective practice as ESL teachers-to-be.

\section{REFERENCES}

Afshar, H. S., \& Farahani, M. (2015). Reflective thinking and reflective teaching among Iranian EFL teachers: Do gender and teaching experience make a difference? Procedia - Social and Behavioral Sciences, 192, 615 620. https://doi.org/10.1016/j.sbspro.2015.06.107

Andreotti, V. (2006). Soft versus critical global citizenship education. Policy \& Practice: A Development Education Review, 3, 40-51. Retrieved from https://www.developmenteducationreview.com/issue/issue-3/soft-versuscritical-global-citizenship-education

Bahagian Pendidikan Guru. (2009). Standard Guru Malaysia [Malaysian Teacher Standards]. Bahagian Pendidikan Guru

Bain, J. D., Ballantyne, R., Mills, C., \& Lester, N. C. (2002). Reflecting on practice: Student teachers' perspectives. Post Press.

Baskara, F. X. R. (2017). Humanistic language learning in the 21st century classroom: A brief look at practice and application. Paper presented at 
92 TEFLIN Journal, Volume 32, Number 1, January 2021

Seminar Dies ke-24 Fakultas Sastra "Cerdas dan Humanis di Era Digital: Perspektif Bahasa, Sastra, dan Sejarah" at Universitas Sanata Dharma, Central Java, Indonesia. Retrieved from https://www.usd.ac.id/fakultas/sastra/sasing/f113/Dies\%2024/Humanistic \%20Language \%20Learning\%20in\%20the\%2021 st\%20Century\%20Classr oom.pdf

Bloomquist, D. L. (2016). The effects of coaching using a reflective framework on early childhood science teachers' depth of reflection and change in practice (Publication No. 10307156). (Doctoral dissertation, University of Toledo, Ohio, USA). Retrieved from ProQuest Dissertations \& Theses Global.

Borg, S. (2015). Teacher cognition and language education. Bloomsbury Publishing.

Bryan, A., Clarke, M., \& Drudy, S. (2009). Social justice education in initial teacher education: A cross border perspective, A report for the Standing Conference on Teacher Education Northand South (SCoTens). Retrieved from http://scotens.org/wp-content/uploads/Social-JuscticeEducation-inInitial-Teac her-Education-2009.pdf

Chien, C. (2014). Pre-service elementary school English teachers' learning and reflection through simulated teaching practice and oral interviews. Reflective Practice, 15(6), 821-835. https://doi.org/10.1080/14623943.2014.944139

Ciampa, K., \& Gallagher, T. L. (2015). Blogging to enhance in-service teachers' professional learning and development during collaborative inquiry. Educational Technology Research and Development, 63(6), 883913. https://doi.org/10.1007/s11423-015-9404-7

Farrell, T. S. C. (2015). Promoting teacher reflection in second language education: A framework for TESOL professionals. Routledge.

Farrell, T. S. C. (2016). Anniversary article: The practices of encouraging TESOL teachers to engage in reflective practice: An appraisal of recent research contributions. Language Teaching Research, 20(2), 223-247. https://doi.org/10.1177\%2F1362168815617335

Farrell, T. S. C. (2019). Standing on the shoulders of giants : Interpreting reflective practice in TESOL. Iranian Journal of Language Teaching Research, 7(3), 1-14. https://dx.doi.org/10.30466/ijltr.2019.120733 
Ong et al., Promoting Reflective Practice via the Use of CoPORA Reflective Model 93

Garza, R., \& Smith, S. F. (2015). Pre-service teachers' blog reflections: Illuminating their growth and development. Cogent Education, 2(1), 1-15. https://doi.org/10.1080/2331186X.2015.1066550

Goh, P. S. C. (2012). The Malaysian Teacher Standards: A look at the challenges and implications for teacher educators. Educational Research for Policy and Practice, 11(2), 73-87. https://doi.org/10.1007/s10671-0119107-8

Goldman, J. D. G., \& Grimbeek, P. (2015). Pre-service primary school teachers' self-reflective competencies in their own teaching. European Journal of Psychology of Education, 30(2), 189-207. https://doi.org/10.1007/s10212-014-0231-8

Guba, E. (1981). ERIC / ECTJ Annual review paper criteria for assessing the trustworthiness of naturalistic inquiries. Educational Communication and Technology, 29(4), 75-91.

Haverback, H., \& Parault, S. (2008). Pre-service reading teacher efficacy and tutoring: A review. Educational Psychology Review, 20, 237-255. https://doi.org/10.1007/s10648-008-9077-4

He, Y., \& Prater, K. (2014). Writing together, learning together: Teacher development through community service learning. Teachers and Teaching, 20(1), 32-44. https://doi.org/10.1080/13540602.2013.848512

Hrevnack, J. R. (2011). Guided development of reflective thinking in the observations of classroom teachers by pre-service candidates. Academy of Educational Leadership Journal, 15(2), 81-93.

Kolb, D. (1984). Experiential learning as the science of learning and development. Prentice Hall.

Kori, K., Pedaste, M., Leijen, Ä., \& Mäeots, M. (2014). Supporting reflection in technology-enhanced learning. Educational Research Review, 11, 4555. https://doi.org/10.1016/j.edurev.2013.11.003

Korthagen, F. (2017). Inconvenient truths about teacher learning: towards professional development 3.0. Teachers and Teaching, 23(4), 387-405.

Korthagen, F. A. J., \& Vasalos, A. (2005). Levels in reflection: Core reflection as a means to enhance professional development. Teachers and Teaching, 11(1), 47-71. https://doi.org/10.1080/13540602.2016.1211523

Krishnan, V. N. G., \& Yunus, M. M. (2017). Reflective practice with eportfolio. Malaysian Journal of ELT Research (MAJER), 13(1), 43-54. 
94 TEFLIN Journal, Volume 32, Number 1, January 2021

Lane, R., McMaster, H., Adnum, J., \& Cavanagh, M. (2014). Quality reflective practice in teacher education: A journey towards shared understanding. Reflective Practice, 15(4), 481-494. https://doi.org/10.1080/14623943.2014.900022

Larrivee, B. (2008). Development of a tool to assess teacher's level of reflective practice. Reflective Practice, 9(3), 341-360. https://doi.org/10.1080/14623940802207451

Lim, H. L., Wun, T. Y., \& Chew, C. M. (2016). Preservice teachers' assessment knowledge : Do teaching experiences make a difference? Journal of Research, Policy \& Practice of Teachers \& Teacher Education, 6(2), 1622. Retrieved from https://ejournal.upsi.edu.my/index.php/JRPPTTE/article/view/222

Mann, S., \& Walsh, S. (2013). RP or "RIP": A critical perspective on reflective practice. Applied Linguistics Review, 4(2), 291-315. https://doi.org/10.1515/applirev-2013-0013

Mena-Marcos, J., \& García-Rodríguez, M.-L., \& Tillema, H. (2013). Student teacher reflective writing: What does it reveal? European Journal of Teacher Education, 36(2), 147-163. https://doi.org/10.1080/02619768.2012.713933

Merriam, S. B. (1998). Qualitative research and case study applications in education. Jossey-Bass.

Merriam, S. B. (2007). Qualitative research and case study applications in education: Revised and expanded from case study research in education. Jossey-Bass.

Mohammed, R. (2016). Critical incident analysis: Reflections of a teacher educator. Research in Teacher Education, 6(1), 25-29. https://doi.org/10.15123/PUB.5093

Moradkhani, S., Raygan, A., \& Moein, M. S. (2017). Iranian EFL teachers' reflective practices and self-efficacy: Exploring possible relationships. System, 65, 1-14. https://doi.org/10.1016/j.system.2016.12.011

Mukhtar, M. A., Hasim, Z., \& Yunus, M. M. (2018). The efficacy of simulated teaching in preparing pre-service teachers for practicum. Journal of Nusantara Studies (JONUS), 3(1), 64-74. https://doi.org/10.24200/jonus.vol3iss1pp64-74

Ong, T. E., Abdul Rahman, N., Wahid, R., Mazuwai, A., Mohd Tajudin, N., Yahya, R. S. A., \& Kosni, A. N. (2017). The character of teaching 
practices in a teacher education institution: Findings from observation checklist. Journal of Research, Policy \& Practice of Teachers \& Teacher Education, 7(2), 33-45. https://doi.org/10.37134/jrpptte.vo17.no2.4.2017

Ong, W. A., Swanto, S., \& Alsaqqaf, A. (2018). Pre-service ESL teachers engaging in reflective practice: Current observations and perceived challenges. Journal of Research, Policy \& Practice of Teachers \& Teacher Education, 8(2), 5-18. https://doi.org/10.37134/jrpptte.vol8.no2.2.2018

Rodgers, C. (2002). Defining reflection: Another look at John Dewey and reflective thinking. Teachers College Record, 104(4), 842-866.

Sanchez-Cortes, D., Kumano, S., Otsuka, K., \& Gatica-Perez, D. (2015). In the mood for vlog: Multimodal inference in conversational social video. $A C M$ Transactions on Interactive Intelligent Systems, 5(2), 1-24. https://doi.org/10.1145/2641577

Sandelowski, M. (1998). The call to experts in qualitative research. Research in Nursing \& Health, 21(5), 467-471. https://doi.org/10.1002/(SICI)1098240X(199810)21:5\%3C467::AID-NUR9\%3E3.0.CO;2-L

Sherin, M., \& Russ, R. S. (2014). Teacher noticing via video: The role of interpretive frames. In B. Calandra \& P. J. Rich (Eds.), Digital video for teacher education: Research and practice (pp. 3-20). Routledge.

Suppiah, S., Lee, K. W., Swanto, S., \& Lajium, D. A. (2019). Insights on ESL student teachers reflecting collaboratively online. English Teacher Journal, 48(2), 82-99.

Taylor, S. G. (2013). Vlogging composition: Making content dynamic. Hybrid Pedagogy Journal. Retrieved from http://hybridpedagogy.org/vloggingcomposition-making-content-dynamic/

Toom, A., Husu, J., \& Patrikainen, S. (2015). Student teachers' patterns of reflection in the context of teaching practice. European Journal of Teacher Education, 38(3), 320-340. https://doi.org/10.1080/02619768.2014.943731

Tripp, D. (1993). Critical incidents in teaching: Developing professional judgement. Routledge.

van Maanen, J. (1983). Qualitative methodology. Sage Publications.

Wlodarsky, R., \& Walters, H. (2010). Use of the reflective judgment model as a reference tool for assessing the reflective capacity of teacher educators in a college setting. I-Manager's Journal on Educational Psychology, 4(1), 13-20. Retrieved from https://files.eric.ed.gov/fulltext/EJ1102369.pdf 
96 TEFLIN Journal, Volume 32, Number 1, January 2021

Wong, Y. M., Mansor, R., \& Samsudin, S. (2015). The challenge of producing progressive teachers in Malaysia: A case study of reflective writings among UPSI student teachers. GEOGRAFIA Online Malaysian Journal of Society and Space, 7(7), 21-32. Retrieved from https://ejournal.ukm.my/gmjss/article/view/18787/6017

Yaacob, A., Walters, L. M., Ali, R. M., Abdullah, S. S., \& Walters, T. (2014). Reflecting on Malaysian teacher trainees' journals. Malaysian Journal of Learning and Instruction, 11(1), 1-21. Retrieved from https://files.eric.ed.gov/fulltext/EJ1137246.pdf

Yang, S. H. (2009). Using blogs to enhance critical reflection and community of practice. Educational Technology and Society, 12(2), 11-21. Retrieved from https://www.ds.unipi.gr/et\&s/journals/12_2/2.pdf

Yin, R. K. (2014). Case study research: Design and methods (5th Ed.). Sage Publication. 